\title{
SURFACE CHARACTERIZATION OF TITANIUM ALLOYS FOR NITROGEN ION IMPLANTATION
}

\author{
Petr Vertat $^{a, *}$, Jan DrahokoupiL $^{b}$, Petr $_{\text {VlcaK }}^{c}$ \\ a Department of Solid State Engineering, FNSPE CTU in Prague, Trojanova 13, 120 00, Prague 2, Czech \\ Republic \\ ${ }^{b}$ Department of Advanced Structural Materials, Institute of Physics AS CR, Na Slovance 2, 182 21, Prague 8, \\ Czech Republic \\ ${ }^{c}$ Department of Physics, FME CTU in Prague, Technicka 4, 166 07, Prague 6, Czech Republic \\ * corresponding author: vertatp@gmail.com
}

\begin{abstract}
Ion implantation is one of the modern methods of the surface modification of various materials. Industrially used $\mathrm{Ti}-6 \mathrm{Al}-4 \mathrm{~V}$ titanium alloy and commercially pure $\mathrm{Ti}$ grade 2 were characterized using the $\mathrm{X}$-ray diffraction methods. Texture of the material and dependence of the microstructural properties on the method of the surface modification were examined in order to determine suitable conditions for application of the process in the industry. The structure of Ti-6Al-4V alloy before and after the nitrogen ion implantation process is discussed and observed surface hardening is explained.
\end{abstract}

KEYwORDs: Ti-6Al-4V, Ti grade 2, Ion implantation, X-ray diffraction.

\section{INTRODUCTION}

Ti-6Al-4V titanium alloy (also called Ti grade 5) and commercially pure $\mathrm{Ti}$ grade 2 are materials widely used in the industry and the biomedicine for their low density, high tensile strength, biocompatibility and resistance to corrosion in some common environments. Disadvantages of the titanium alloys for their applications are their poor performance in sliding, insufficient surface hardness and insufficient resistance to some chemical environments. For these reasons is the surface of common titanium alloys often modified.

Nowadays, one of the most suitable surface modification methods seems to be the ion implantation of nitrogen ions into the surface of the sample. It has been shown that mechanical qualities and wear and corrosion resistance of many materials can be improved using this method. Concerning the titanium and its alloys, creation of hard $\operatorname{TiN}_{x}$ phases [1] or stabilization of the $\alpha$-Ti phase [2] leading to the increase of the surface hardness is expected.

Compared to the other commonly used surface modification methods, the advantages of the nitrogen ion implantation are the ability to control the process precisely (esp. the fluence of the implanted ions, their energy and thus the depth distribution) and so the ability of automating the process and the possibility to implant at the low temperatures.

\section{EXPERIMENTAL DETAILS}

For purpose of characterizing the sample preparation method and the surface modification using the nitrogen ion implantation the $\mathrm{Ti}-6 \mathrm{Al}-4 \mathrm{~V}$ (Ti grade 5 ) alloy with a microstructure consisting of the $\alpha+\beta \mathrm{Ti}$ phases with a chemical composition of (wt\% $0.1 \% \mathrm{C}$,
$5.50-6.75 \% \mathrm{Al}, 3.50-4.50 \% \mathrm{~V}, 0.2 \% \mathrm{O}, 0.05 \% \mathrm{~N}$, $0.0125 \% \mathrm{H}, 0.3 \% \mathrm{Fe}$ and $\mathrm{Ti}$ balance) and the Ti grade 2 consisting mainly of the $\alpha$-Ti phase, chemical composition of (max. wt $\% 0.08 \% \mathrm{C}, 0.25 \% \mathrm{O}$, $0.03 \% \mathrm{~N}, 0.015 \% \mathrm{H}, 0.3 \% \mathrm{Fe}$ and $\mathrm{Ti}$ balance), were examined.

The disc samples were cut from commercially available bars, ground and polished with a diamond paste in order to obtain a flat smooth surface suitable for the ion implantation.

Phase composition of the polycrystalline samples, microstrain and texture were determined using the $\mathrm{X}$-ray diffraction. Data were measured on the PANalytical X'Pert PRO horizontal powder diffractometer with a cobalt anode $\left(\lambda_{K \alpha_{1}}=0.1789 \mathrm{~nm}\right)$ using the divergent Bragg-Brentano geometry and parallel beam geometry. For pole figures measurements the ATC- 3 texture cradle was used allowing rotation of the sample in the $\phi$ angle, change of the inclination angle $\chi$ and horizontal movement of the sample. For temperature dependences the HTK 2000 heating chamber was used. Measured data were processed by Rietveld analysis using the TOPAS 3 software. In this method the measured diffraction pattern is compared with the calculated one and the input parameters are varied on the basis of differences between them. For the calculation of diffraction pattern, this program uses so called "fundamental parameter approach" [3, i.e. that the calculated diffraction profile is based on convolution of particular contributions to the total profile. Three components of diffraction peak broadening are taken into account: an instrumental broadening, an average crystallite size and microstrains. Thus 


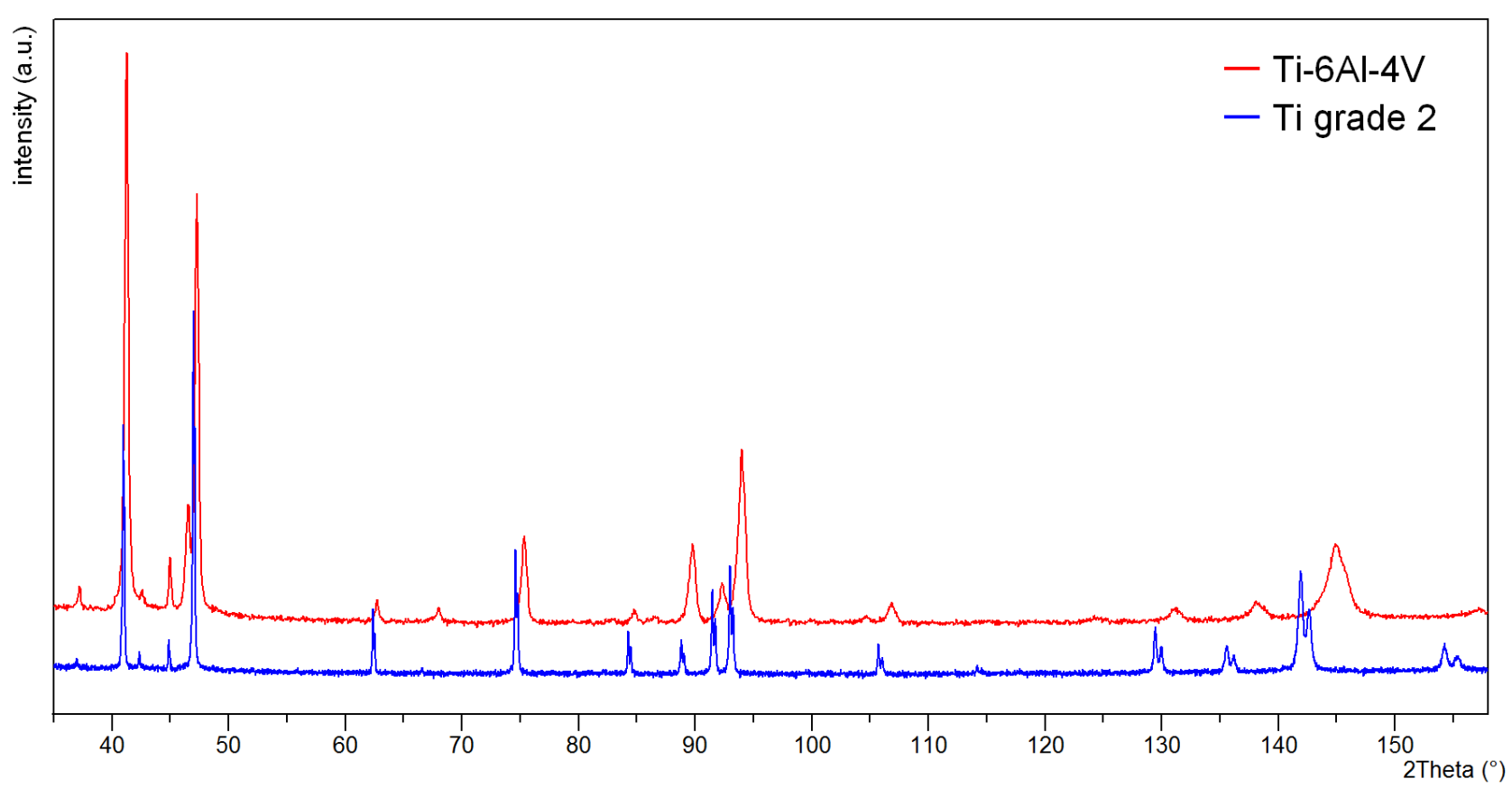

Figure 1. Measured diffraction patterns of the Ti-6Al-4V and Ti grade 2 samples.

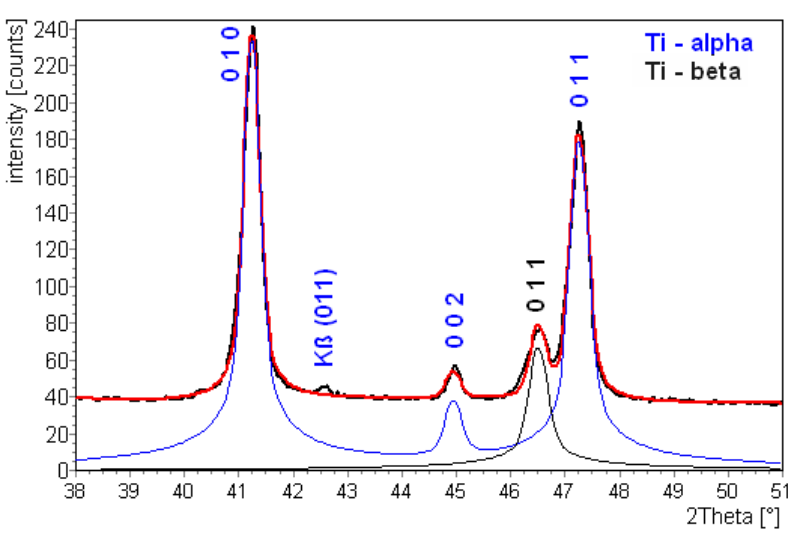

Figure 2. Detailed diffraction diagram of the $\mathrm{Ti}-$ $6 \mathrm{Al}-4 \mathrm{~V}$ sample. Both present titanium phases: $\alpha-\mathrm{Ti}$ and $\beta-\mathrm{Ti}$ are marked using different colors and their reflections are indexed. Rietveld fit of the measured data is marked with red color.

precise determination of average crystallite sizes and microstrains is possible.

The pole figures for reflections 100, 002, 110 and 101 were measured using the reflection geometry. The inability of this method to measure the whole pole figures was solved by calculation of the ODF function followed by recalculation of desired pole figures. The background and defocusing corrections were applied using the homemade software. Calculation of the ODF and recalculation of the pole figures were made in the X'Pert Texture program.

In order to verify the effect of the nitrogen ion implantation on the surface properties of the $\mathrm{Ti}-$ $6 \mathrm{Al}-4 \mathrm{~V}$ alloy and in order to explain such possible effect, samples were implanted using the Ion Implanter TECVAC 221 in conventional setup - the fluency of

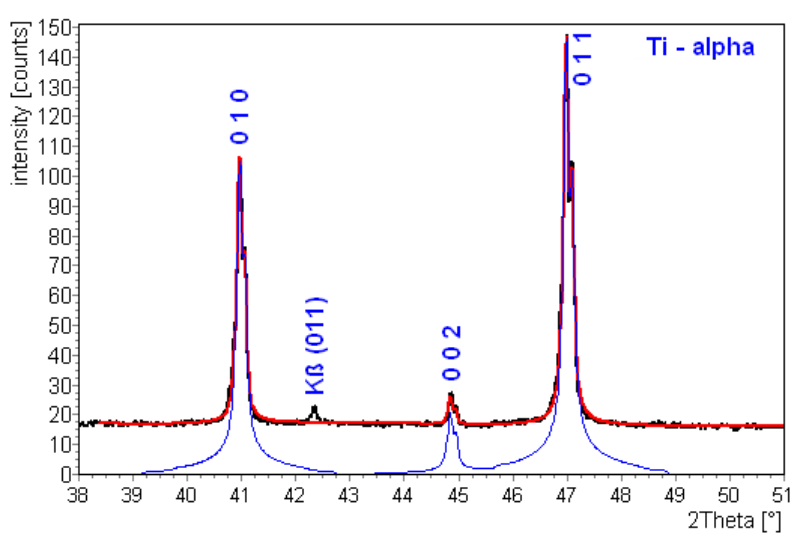

Figure 3. Detailed diffraction diagram of the Ti grade 2 sample, only the $\alpha$-Ti phase (blue line, corresponding Miller indices are shown) is present. Rietveld fit of the measured data is marked with red color.

$6 \cdot 10^{17} \mathrm{~cm}^{-2}$ and the $90 \mathrm{keV}$ accelerating voltage at the temperatures lower than $80^{\circ} \mathrm{C}$.

\section{Results And Discussion}

\subsection{SAMPLES CHARACTERIZATION BEFORE THE NITROGEN ION IMPLANTATION}

Ti-6Al-4V and Ti grade 2 samples were examined using the methods of the $\mathrm{X}$-ray diffraction analysis, measured diffraction patterns are shown in Figure 1. Differences in the peak positions are caused by the different chemical compositions of the alloys. Measurements of the Ti-6Al-4V sample (detailed view in Figure 22 showed the presence of two titanium structures: hexagonal $\alpha$-Ti (76\%) phase and cubic $\beta$-Ti (24\%). In the Ti grade 2 sample only $\alpha$-Ti phase 

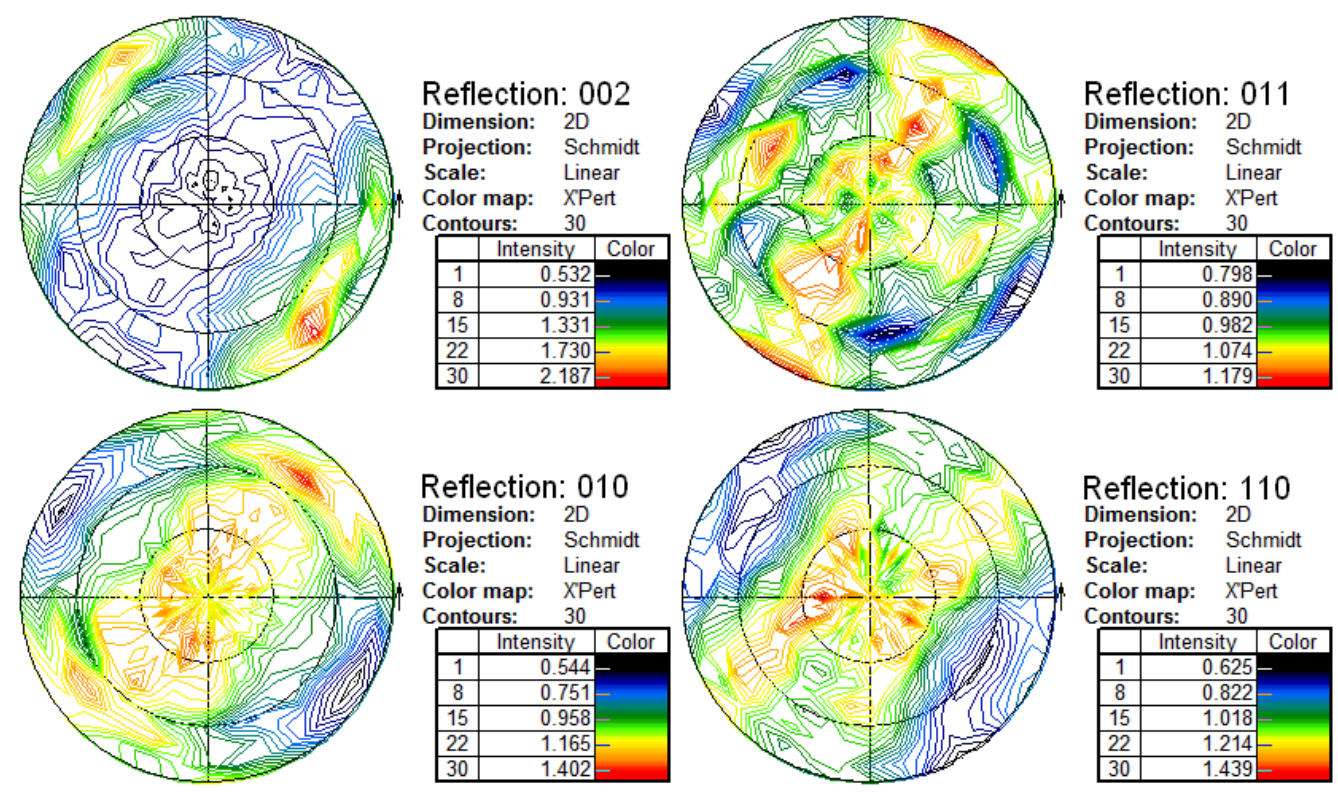

FigurE 4. Recalculated direct pole figures of the 002, 010, 011 and 110 reflections of the Ti grade 2 sample.

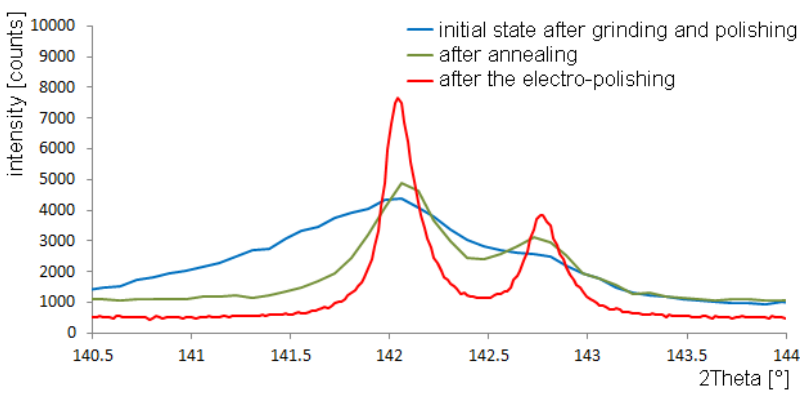

Figure 5. Detail of the diffraction profile of the Ti grade 2 sample (reflection 211 of the $\alpha$-Ti phase) after different preparation treatment.

was present. Diffraction diagram of Ti grade 2 sample after the electro-polishing might be seen in Figure 3 .

The texture analysis shows the samples are textured (Figure 4). The crystallographic direction 001 has low rate in the direction that is normal to the surface of the sample. Although the samples physicaly have the rotational symmetry, the pole figures reveal only the mirror symmetry of the inner microstructure. This has to be taken into account when doing other XRD measurements, namely measurements with the inclined sample or with fixed incident angle.

Influence of the sample preparation on the microstructure of Ti grade 2 has also been studied. Detailed look on the diffraction profiles of the sample treated only by grinding and polishing using the diamond paste reveals broadening of the diffraction lines indicating lower crystallite size and higher microstrain in the structure. Considerable asymmetry indicates the depth gradient of the macroscopic residual stress (Figure 5). In an effort to eliminate such effects that have arisen due to the preparation of the sample, influence of the electrolytic polishing and annealing on the microstructure was examined.

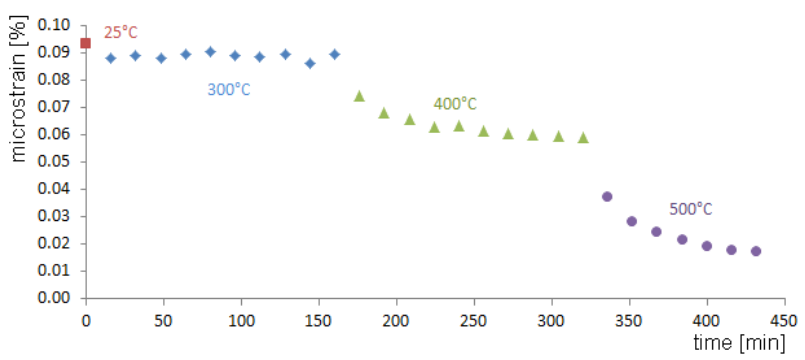

FIGURE 6. Time dependence of the microstrain during the annealing of the Ti grade 2 sample. Annealing temperatures are distinguished using different colors. Initial value at the room temperature obtained after grinding and polishing the sample using a diamond paste is also shown. Absolute error $<0.003 \%$.

Diffraction profiles measured after the mentioned procedures are shown in Figure 5

Measured influence of the annealing at different temperatures $\left(300{ }^{\circ} \mathrm{C}, 400{ }^{\circ} \mathrm{C}\right.$ and $\left.500{ }^{\circ} \mathrm{C}\right)$ on the microstrain is shown in Figure 6representing the time dependence of this quantity. The dominant effect of removing the residual microstresses is reached during the first minutes after reaching particular temperature. For the temperature of $300{ }^{\circ} \mathrm{C}$ there is no visible progress after several minutes at all. For higher temperatures there is a jump followed by a continuous decreasing of microstrains.

The results show sufficient decrease of the microstrain value when compared with the initial state of the sample after its necessary treatment by grinding and polishing using the diamond paste. However, the influence of the sample preparation is not eliminated completely.

State closest to the initial microstructure of the bulk sample is revealed (according to Figure 5 by the electro-polishing. Under the common circumstances 


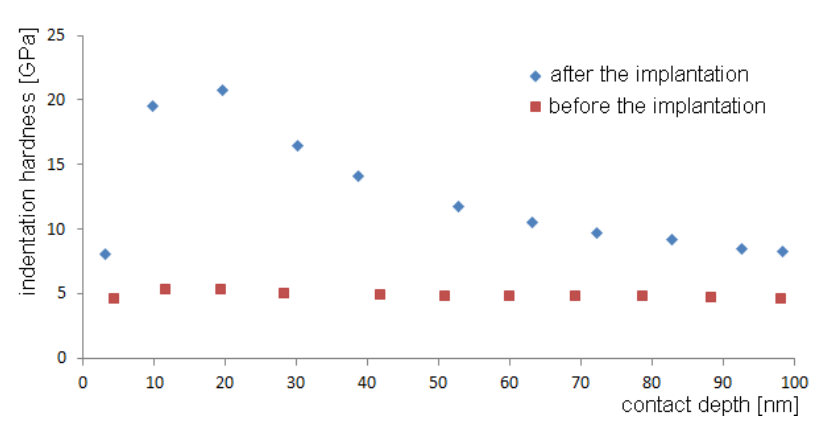

FiguRE 7. Depth profile of the indentation hardness measured on $\mathrm{Ti}-6 \mathrm{Al}-4 \mathrm{~V}$ sample before and after the nitrogen ion implantation. 4] Values influenced by the relative error originating from the calibration $\sim 10 \%$.

this method of the surface treatment can be considered as the most suitable one. Regarding the $\mathrm{Ti}-6 \mathrm{Al}-4 \mathrm{~V}$ alloy, analogous behavior can be expected.

\subsection{SAMPLES CHARACTERIZATION AFTER THE NITROGEN ION IMPLANTATION}

After the nitrogen ion implantation into $\mathrm{Ti}-6 \mathrm{Al}-4 \mathrm{~V}$ samples using the suitable implantation parameters, desired surface hardening is observed as proven by the typical depth profile of the nanoindentation hardness (Figure 7) [4].

Phase composition of the $\mathrm{Ti}-6 \mathrm{Al}-4 \mathrm{~V}$ samples after the implantation with parameters described in section 2 was characterized. In addition to hexagonal $\alpha$-Ti and cubic $\beta$-Ti phases observed before the implantation, two new phases were detected: smaller amount of the solid solution $\alpha-\mathrm{Ti}(+\mathrm{N})$ and majority of the TiN solid phase. Formation of these two phases describes the mechanism of observed surface hardening in our alloy.

Dependences of different implantation parameters on concrete phase composition and mechanical properties of mentioned titanium alloys are now the object of further research.

\section{Conclusions}

Samples of $\mathrm{Ti}-6 \mathrm{Al}-4 \mathrm{~V}$ ( $\mathrm{Ti}$ grade 5) and $\mathrm{Ti}$ grade 2 alloys were characterized by the $\mathrm{X}$-ray diffraction methods. Texture in the samples of such commonly available materials and improvement of their microstructural properties by annealing at different temperatures and by electro-polishing were discussed. Best results were obtained using the last method.

Presented results create the precondition for a further research in the field of functionalizing the surface of Ti-6Al-4V and Ti grade 2 alloys aiming mainly at characterizing the influence of various ion implantation parameters on the phase composition and physical properties of these materials for their future application in the industry and biomedicine.

\section{ACKNOWLEDGEMENTS}

Authors thank dr. J. Sepitka for the nanoindentation measurements. This work was supported by the Grant Agency of the Czech Technical University in Prague, grant No. SGS16/245/OHK4/3T/14, and Czech Science Foundation, grant No. 16-22276S.

\section{REFERENCES}

[1] Y. Z. Liu, X. T. Zu, S. Y. Qiu, J. Cao, C. X. Li, X. Q. Huang, C. F. Wei: Phase formation and modification of corrosion property of nitrogen implanted TiAlV alloy. Vacuum 81 (1):71-76, 2006. doi: 10.1016/j.vacuum.2006.02.013

[2] H. Schmidt., A. Schminke, M. Schmiedgen, B. Baretzky: Compound formation and abrasion resistance of ionimplanted Ti6Al4V. Acta Mater. 49 (3):487-495, 2001. doi: 10.1016/S1359-6454(00)00326-8

[3] R. W. Cheary, A. A. Coelho, J. P. Cline: Fundamental Parameters Line Profile Fitting in Laboratory Diffractometers. J. Res. Natl. Inst. Stand. Technol. 109:1-25, 2004. doi: 10.6028/jres.109.002

[4] P. Vlcak, F. Cerny, J. Drahokoupil, J. Sepitka, Z. Tolde: The microstructure and surface hardness of Ti6Al4V alloy implanted with nitrogen ions at an elevated temperature. J. Alloys Compd. 620:48-54, 2015. doi: 10.1016/j.jallcom.2014.09.125 